\title{
Grammaticalisation of Pelhi:n in Haili Arabic- From Propositional Item to Discourse Particle: Split CP Investigation
}

\author{
Murdhy R. Alshamari \\ Department of English Language, The University of Ha'il, Ha'il, Saudi Arabia
}

\begin{abstract}
This paper explores the linguistic properties of a discourse variant of the temporal adverb Pelhi:n, used in Haili Dialect of Najdi Arabic (HA). Maintaining the characteristic of co-occurring clause-initially, and examining lexical/discoursal articulated structures, Pelhi:n has developed a conventionalized discourse use, turning its morphology into a discourse particle that expresses a degree of speaker's attitude. 2elhi:n has undergone a process of grammaticalisation, with morphosyntactic consequence: changing its phrasal status to a head one. Evidence supporting this direction derives from intervention effects (Rizzi, 2006)- Pelhi:n inhabits movement of head-items in syntax. The immediate consequence of this morphosyntactic change has direct impact on the syntax of Pelhi:n: occurring clause-initially and its phonology: being unable to bear high tone, unlike its temporal adverb counterpart. Implementing cartographic mechanisms, Rizzi's (1997) Split CP System, and holding to observations that inherently focused material wh-phrase leIf 'why' merges in a

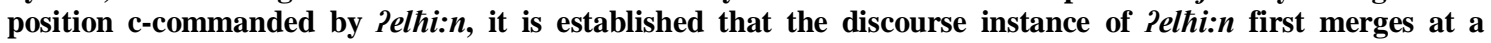
discourse head, instantiating a discourse projection, PrtP, whence it semantically wide-scopes the propositional-TP. Constituents preceding Pelhi:n are then argued to move and remerge at some Spec of a discourse phrase, C-TopP (Frascarelli \& Hinterhölzl, 2007). Mapping the CP-layer of HA, the PrtP headed by Pelhi:n maintains a rigid order in syntax with respect to $\mathrm{CP}$-items, which makes a possible, initial mapping to the left periphery of $\mathrm{HA}$, calling for scrutiny of more structure.
\end{abstract}

Index Terms - grammaticalisation, split CP, discourse particle, temporality, movement

\section{INTRODUCTION}

The syntax and semantics of the lexical item representing the temporal interpretation 'at the moment', the crosslinguistic variant of the English instance of now, having a discourse semantic import in some contexts, has been intensively investigated, implementing a range of theoretical and formal approaches (Aijmer, 2002; Brinton, 1996). Investigating the semantics of now, in particular, corpus of collocations where now occurs, Bolinger (1989) argues that now in some environments functions as a discourse marker implemented for change of topic in the ongoing discourse. Stenström (1990) establishes that now that bears a high tone is evidence that it functions as a temporal adverb, while the instance of now without a high tone functions as a discourse particle. Building on the consensus that high tone is a criterion to distinguish the use of now, Hirschberg \& Litman (1993) investigate the use of now using syntactic and prosodic feature-based strategies as a criterion to draw a distinction between the temporal function and the discourse function of now. One of the facts their research raises is that discourse now maintains low tone that the temporal now. Another fact they raise is that, in most, but not all cases, there is a correlation between occurring clause-initially and functioning as a discourse particle. From this, then, it follows that the discourse now co-occurs with items expressing past-tense adverbs like then (Schiffrin, 1987; Aijmer, 2002). Further, Fraser (1990, p. 388) distinguishes the use of now in (1) below from other uses, where he argues that being separated by a phonological pause, now in (1) is a separate tone unit, hence a prosodic account to the argument that now in (1) is a discourse particle, in particular, Focus marker.

(1) John left. Now, Mary was really frightened.

Aijmer (2002) provides further the data in (2), in which now in Speaker B's utterance contains discourse now, functioning as a continuation or elaboration of what has just been said about John in Speaker A's utterance.

(2) Speaker A. That man speaks extremely good English.

Speaker B. Now he comes from a village in Mongolia.

Recent research on now has focused on the grammaticalised status of now, arguing that now has developed a discourse functional rather than a temporal interpretation. With respect to this, Aijmer (2002), following Bolinger (1989), further maintains that now in English has grammaticalised, having a multifunctionality property, in which it has developed a discourse function, in particular, a topic change device. Jarrah et al. (2020, p.6), using a huge range of corpus data, establish that the Jordanian variant of now, Pil?a:n functioning as a deictic temporal adverb, has developed a discourse function, facilitating the speaker-hearer communication, which can bear the meaning of phrases like at this point/given this. 
This property of now seems to be cross-linguistic. For instance, in addition to its function as a temporal adverbial, the French variant maintenant functions as a discourse marker that creates a contrast between a previous and a current content of an utterance (Bertin, 2001). Hebrew also manifests this discourse property of now. Consider the extract in (3) below, from Gonen et al. (2015, p.73).

(3)

Speaker A: Aval anaxnu asinu et ze beyaxad

'But we did it together.'

Ve-hitya' atsnu etsel orex din ma osim shlav

'And we consulted with a lawyer what to do at each stage.'

Kdey sheshu lo yafsid

'So that he wouldn't lose.'

Speaker B: ken

'yes.'

Speaker A: kdey sheyitxalek be'emet xetsi

'so that it would really be split 50-50.'

Axshav gam asur haya lanu lehera' ot beyaxad

Now we weren't allowed to be seen together either.'

Ki hi yaxla lehagid hu bogged bi

'because she could say he's cheating on me.'

Vegam hu lo haya mekabel klum

'and also, he wouldn't get anything

Gonen et al. (2015) investigate the Hebrew now variant, axshav, maintaining that it occurs cluse-initially in Speaker A's second utterance in (3), functions as discourse marker which helps a discourse shifting device. This, they argue, is associated with two observations; axshav is deaccented at the phonological interface and is used at the beginning of a discourse fragment in syntax, where the speaker wants to introduce a new topic to the ongoing conversation.

Given this background on the discourse-related now, with special focus on (i) the grammaticalisation status of the discourse-related now and (ii) the tendency of the discourse-related now to occur clause-initially and (iii) the phonological property of discourse-related now not bearing high tone, i.e., discourse-related now is deaccented, the current research will be an investigation to the syntactic item now '?elhi:n', used in Haili Arabic, spoken in Saudi Arabia. Using generative cartographic assumptions, the current paper will take up the issues stated in (i), (ii) and (iii) into consideration, linking the discourse function of discourse now, to its syntactic position and its morphological and morphosyntactic statuses, with an account to its possible grammaticalisation status and discourse interpretation.

The paper is structured as follows. Section 2 touches upon the syntactic and interpretive properties of Pelhi:n, including its temporal and discoursal marking as well as the syntactic positions it occupies. Section 3 sets an investigation to the morphosyntax and syntax of the discourse instance of Pelhi:n, showing that the discourse instance of Pelhi: $n$ is an output of grammaticalisation of temporal instance counterpart, highlighting on a set of consequences like developing a head status in syntax, restricting to clause-initial positions and becoming unable to bear high tone. Section 4 provides a cartographic analysis, showing that it merges in a fixed position in a CP-layer, heading PrtP in syntax, with a discourse feature, whence it scopes over the TP it c-command. Section 5 concludes the paper.

\section{SEMANTIC Distribution OF PELHI:N: TEMPORAL AND DisCOURSAL INTERPRETATIONS}

Before taking up the issue highlighted above, the relevant data shall be displayed, which the analyses ahead will address, including some basic assumptions related to marked/unmarked word order in HA, as this will be crucial in terms of sentential and discoursal statuses of the sentences under analysis. To start with, used in its lexical meaning, the linguistic item ?elhi:n 'now' is categorized as a Temporal adverb, expressing present time, with Temporal value 'at the moment', as in (4) below.

(4) Relhi:n qaSid j-esqi Firas Pez-zerS lhaluh

now Asp 3SG.M-water Firas DEF-grass alone

'Firas is watering the grass alone at the moment.'

The proposition expressed by (4), presenting the state of affairs that Firas is watering the grass at the utterance time, is discourse-neutral, not being associated to any discourse value, or extra-sentential expression, hence, VSO pattern (Ouhalla, 1994, 1997, 2003, 2016; Shlonsky, 2000' Ouhalla \& Shlonsky, 2002; Jarrah 2017; Jarrah \& Abusalim 2021). The subject DP, therefore, being discourse bound, not bearing any information structural value like Focus or Topic, remains at its first merge position, Spec vP, while the lexical verb moves to T due to rich agreement (Ouhalla, 1994, 1997). I therefore represent the scenario in (4) in the schemata in (5) below, in which $\mathrm{v}$, which incorporates $\mathrm{V}$, which in turn contains the lexical verb jesqi, moves and re-merges at T (Ouhalla, 1994, 1997), while the Asp-marker qaSid first merges at T (Chomsky, 1999, 2000, 2001).

$\begin{array}{cccccc}\text { (5) }[\mathrm{CP} \text { TP Pelhi:n } & {[\mathrm{TP}} & \mathrm{T} \text { qaSid } & \mathrm{v}+\mathrm{V} \text { j-esqi } & \text { [vP Firas } & \text { [VP Pez-zerC]]]] } \\ \text { AdvP } & \text { Asp } & \text { 3SG.M-go.PRS Firas } & \text { DEF-grass }\end{array}$

'Firas is watering the grass at the moment.' 


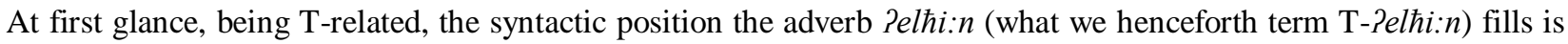
expected by theory, Spec TP, where tense is expressed, which is also dedicated in syntax for T-related items like Temporal adverbs (and other locative PPs, triggered to move to Spec TP for reasons like [EPP]). Consider the

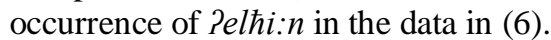

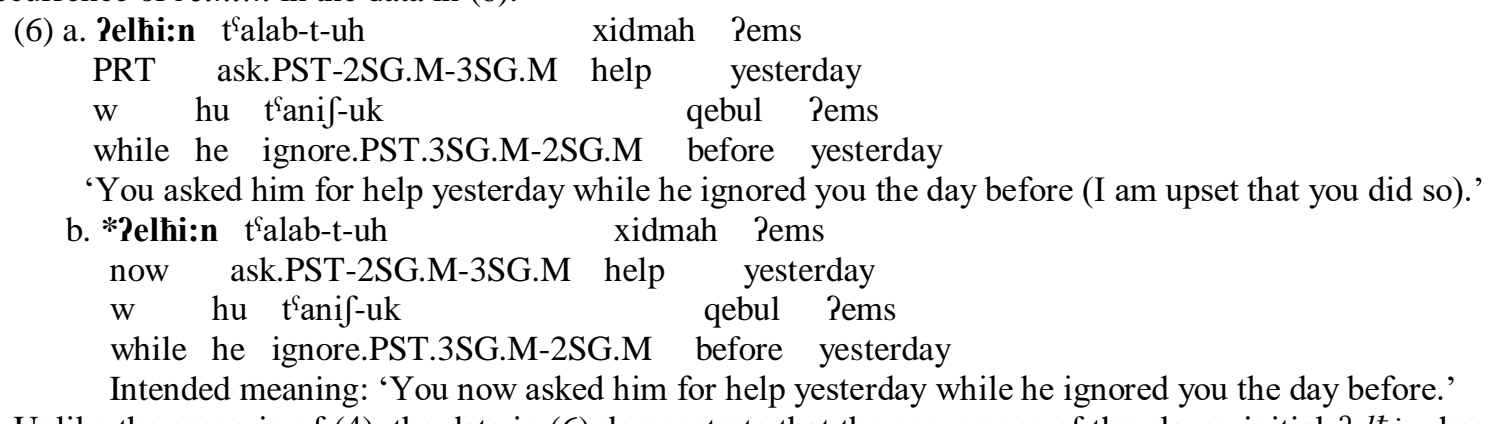

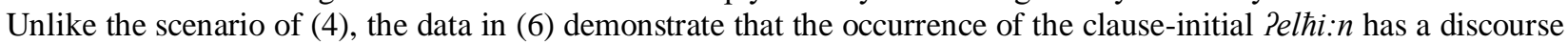
function, rather than temporality marking, where evidence is derived from the observation that in (6b) Pel $i: n$ doesn't correlate with the propositional deictic expression represented by the lexical past-form verb and the past-T-adveials ?ems 'yesterday' and qebul ?ems 'before yesterday'.

Consider now (4), repeated below as (7) with the same syntax, in which Pelhi:n occurs clause-initially, but with entirely different semantic distribution and interpretation.

$\begin{array}{lllll}\text { (7) Pelhi:n } & \text { qaSid } & \text { j-esqi } & \text { Firas } & \text { Pez-zerG lhaluh } \\ \text { PRT } & \text { Asp } & \text { 3SG M-water } & \text { Firas } & \text { DEF-grass }\end{array}$

PRT Asp 3S.M-water Firas DEF-grass alone

'Firas is watering the grass alone at the moment (I am upset that he is doing so).'

The interpretive, semantic distribution Pelhi:n adds to the proposition in (7) is no longer temporal, but discourse related, i.e., encoding a certain degree of surprise at something that the speaker doesn't like, in the sense of Cuenca (2013), which is widely referred to in the literature of discourse particles as speaker negative attitude towards the proposition (Coniglio 2008). Under this view, in par with the propositional content of (6) above, the clause in (8) below is therefore a felicitous continuation of the speaker's discourse in (7), but infelicitous of the one in (4).

(8) $\mathbf{w}$ ?int qil-t rah t-saSd-uh

PRT 2SG.M say.PST.2SG.M FUT 2SG.M-help.PRS-3SG.M

'While you said you would help him (I am upset that you haven't helped him).'

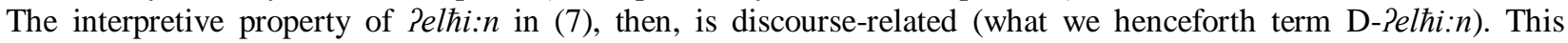
discoursal status of Pelhi:n in (7) and also in (6) is further captured by the fact that the clause has a speaker negative attitude discourse particle $w a$, which functions as a discourse-organizer, activated in the second conjunct (continuation) of the clause.

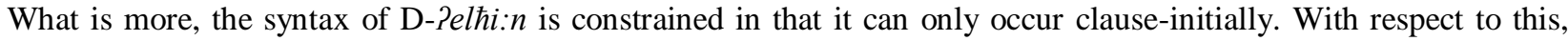

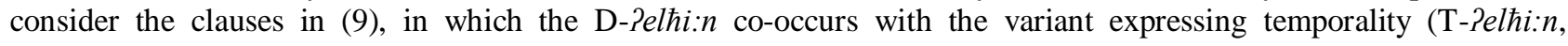
henceforth).

$\begin{array}{cllll}\text { (9) a. Pelhi:n (Pelhi:n) } & \text { qaSid j-esqi } & \text { Firas } & \text { Pez-zerS } \\ \text { PRT now } & \text { Asp } & \text { 3SG.M-water } & \text { Firas } & \text { DEF-grass }\end{array}$

'Firas is watering the grass at the moment (I am upset that he is doing so).'

b. Pelhi:n Pelhi:n (qa9id) j-esqi Firas ?ez-zer؟

PRT now Asp 3SG.M-water Firas DEF-grass

'Firas is watering the grass at the moment (I am upset that he is doing so).'

$\begin{array}{clllll}\text { c. *2ELHI:N } & \text { Pelhi:n } & \text { qaSid } & \text { j-esqi } & \text { Firas } & \text { Pez-zerS } \\ \text { PRT } & \text { now } & \text { Asp } & \text { 3SG.M-water } & \text { Firas } & \text { DEF-grass }\end{array}$

'Firas is watering the grass at the moment (I am upset that he is doing so),'

d.*?elhi:n Pelhi:n qaSid j-esqi Firas Pez-zer؟

now PRT Asp 3SG.M-water Firas DEF-grass

Intended meaning: 'Firas is watering the grass at the moment (I am upset that he is doing so).'

e. 2ELHI:N Pelhi:n qaSid j-esqi Firas ?ez-zerৎ

now PRT Asp 3SG.M-water Firas DEF-grass

'It is AT THE MOMENT that Firas is watering the grass (I am upset he is doing so).'

Notice in passing that progressiveness is marked the Asp-marker qaYid can be achieved by the D-?elhi:n (9a,b). that is, one can do Aspectuality. As we can see, D-Pelhi:n is allowed only clause-initially (9a,b,), as the ungrammaticality in (9d) confirms. This restriction, however, can be remedied if and only if one phonological-semantico condition is met:

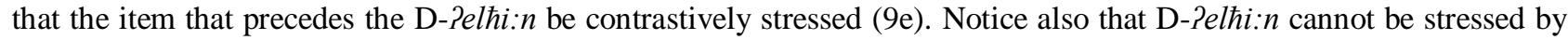

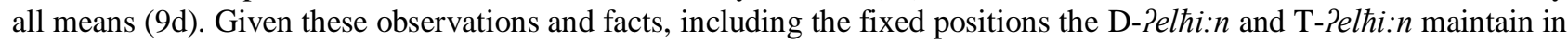
syntax, the following section will explore such phenomena, addressing the pieces of inquiry raised earlier, recapitulated here: (i) the grammaticalisation status of the discourse-related now, (ii) the tendency of discourse discourse-related now 
to occur clause-initially and (iii) the phonological property of discourse-related now not bearing high tone PF-interface, (Chomsky, 2000, 2001). This will require focusing on morphological-syntactic statuses of D-Pelhi:n, linking that to the interface systems' conditions and constraints in the syntax of D-Pelhi:n. I examine the morphological and morphosyntactic distribution of D-Pelhi: $n$ with respect to the clause and the clause internal constituents.

\section{MoRPhOSYNTAX AND SYNTAX OF D-PELHI:N}

\section{A. Morphosyntax: Case of Grammaticalisation of D-Pelhi:n}

In pre-generative approaches to investigating the syntax discourse particles, contributions had always confronted the observation that many discourse particles had counterpart syntactic categories, from which they would have developed historically and with which they co-occur but with different syntactic properties and sematic values, depending on the content of the proportional content of the associate clause (Coniglio \& Zegrean, 2010; Biberauer \& Sheehan, 2011; Biberauer et al., 2014; Hack, 2014; Bayer \& Struckmeier, 2017). This had always resulted in its being difficult to determine a unified categorial status of such items.

As a consequence of this, it was stipulated that discourse particles fit into other syntactic categories like adverbs (Cardinaletti, 2011). For instance, they would maintain fixed rigid order in syntax like adverbs (Büring \& Hartmann, 2001). In generative enterprise, with considerations of movement as a fundamental process of natural language, and with more focus on the functionality property of discourse particles, rather than lexicality, discourse particles, in comparison with their adverbial counterparts, seemed to display sign of intervention effects when item with head status move across them in syntax (Biberauer \& Sheehan, 2011; Biberauer et al., 2014; Hack, 2014; Bayer \& Struckmeier, 2017; Trotzke \& Mayol, 2021). Consider the data below, from Bayer \& Obenauer (2011, p. 1-3).

$$
\begin{aligned}
& \text { (10) a. Der ist vielleicht SÜSS. } \\
& \text { this.MASC is perhaps sweet }
\end{aligned}
$$

'This one (e.g. coffee) is perhaps sweet.'

b. Vielleicht ist der SÜSS.

'Perhaps, this one is sweet.'

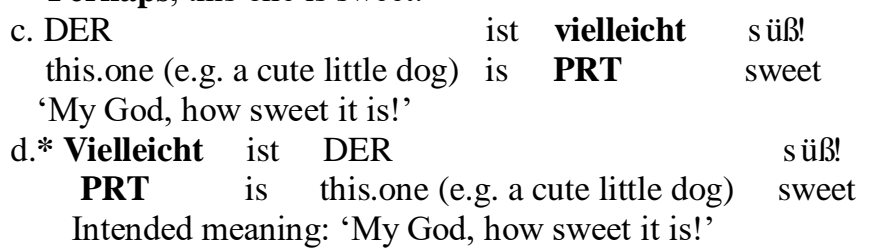

While it moves crossing the finite verb ist to the left periphery when it is categorized as an adverb (10b), Vielleicht is frozen in place when it functions as a discourse particle (10d). Such phenomenon has since arisen the assumption that discourse particles don't move; they are immobile in syntax (Struckmeier, 2014; Bayer \& Trotzke, 2015; Jarrah \& Alshamari, 2017; Alshamari, 2017a, b; Bayer \& Struckmeier, 2017). Further, as an implication to the theory of movement and categorization, captured by the observation that typical adverbs move but discourse markers counterparts don't, it was then argued on empirical groundings that adverbs and their derived discourse particles are entirely different, and that the latter have developed a different semantic property, with the consequence that it's syntactically immobile. Empirical evidence like intervention sensitivity in (10), then, is attributed to another syntactic consequence of the development the discourse particles have undergone; i.e. being sensitive to head movement. This fact follows, on empirical groundings, if discourse markers have a morphosyntactic head status (Coniglio, 2008; Bayer \& Obenauer, 2011; Bayern, 2012; Struckmeier, 2014; Bayer \& Trotzke, 2015; Alshamari, 2017a,b; Jarrah, 2019; Holmberg et al., 2019).

These facts go in line with current research on discourse particles, the assumption that multifunctionality of an item, including discourse function, is sign of a grammaticalised status of this item (Fraser, 1996). Current approach to research on discourse particles has argued that discourse particles are output of grammaticalisation, an assumption which has resulted in the widely held assumption that grammaticalisation is a criterion to distinguish discourse particles from other lexical counterparts, like the usual suspect, adverbs (Traugott, 1995; van Baar, 1996; Aijmer, 2002; Biberauer et al., 2014; Zimmermann, 2011; Biberauer \& Sheehan, 2011; Biberauer et al., 2014; Hack, 2014; Bayer \& Struckmeier, 2017). The set of data below is from Hack (2014, p.55-57), investigating the semantic-change that has occurred to the Italian lexical item po, functioning as an adverb (11a), after which it has grammaticalised into a Tense marker (1b), and later as a wh-question marker (1c).

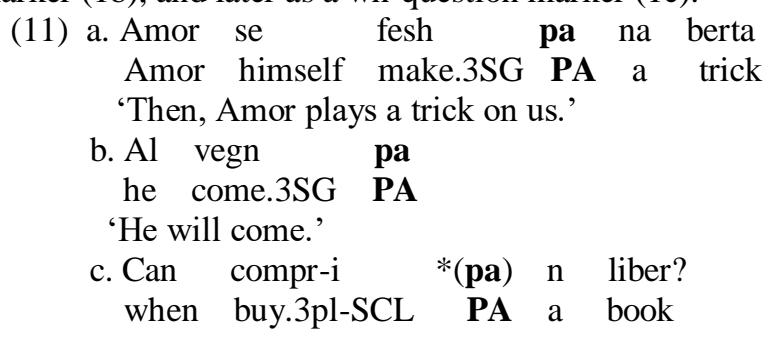


'When are they going to buy a book?'

With grammaticalisation being taken up as a characteristic of discourse particles, the formal characterization of discourse particles is translated into the fact that discourse particles show decrease in lexical meaning and increase in grammatical meaning (Hopper \& Traugott, 2003). As an implication to the semantics-syntax interface of discourse particles, current generative practice on discourse particles argues that a lexical element that undergoes a grammaticalisation process turning into a discourse particle maintains into a syntactic head, with discourse value (Haegeman, 1993; Roberts \& Roussou, 1999; Coniglio \& Zegrean, 2010; Hack, 2014; Bayer \& Trotzke, 2015; Bayer \& Struckmeier, 2017; Biberauer et al., 2014). Extending this logic to D-?elhi:n, the generalization we can now formulate

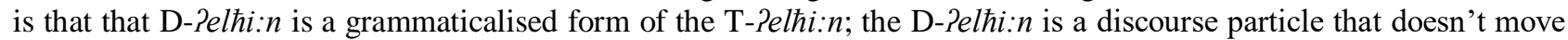
in syntax, being frozen in place where it first merges and which has a discourse feature expressing the structural

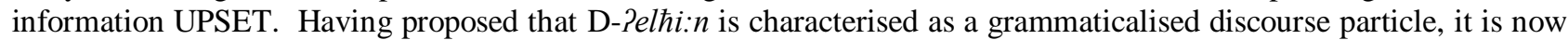
plausible to implement Rizzi's (2006) intervention effects to account for the headedness property of the D-Pelhi:n. I elaborate on this issue in the next sub-section.

\section{B. The Syntax of D-?elhi:n: Headedness Status}

Recall in section 2, in (9e) repeated below as (12), that no items, be it lexical or functional, can precede the D-?elhi:n unless it carries contrastive stress and is introduced by a discourse marker $z a d$, functioning as contrastive topic, in the sense of Frascarelli \& Hinterhölzl (2007). ${ }^{1}$

(12) PELHI:N zad Pelhi:n qaSid j-esqi Firas Pez-zer؟

now CT PRT Asp 3SG.M-water Firas DEF-grass

'It is AT THE MOMENT that Firas is watering the grass (I am upset he is doing so).'

In par with the adverb movement in (12), consider the following data, involving movement of the clause internal arguments $^{2}$.

(13) a. FIRAS zad Pelhi:n Pelhi:n qaSid j-esqi Pez-zerৎ FIRAS CT PRT now Asp 3SG.M-water DEF-grass

'FIRAS is watering the grass at the moment (I am upset that he is doing so).'
b. ?EZ-ZERS
zad Pelhi:n Pelhi:n qaSid j-esqi-h
Firas

DEF-GRASS CT PRT now Asp 3SG.M-water-3SG.M Firas

'THE GRASS, Firas is watering it at the moment (I am upset that he is doing so).'

$\begin{array}{crllll}\text { c. *QASID zad Pelhi:n } & \text { Pelhi:n j-esqi } & \text { Firas } & \text { Pez-zerৎ } \\ \text { Asp } & \text { CT } & \text { PRT now } & \text { 3SG.M-water } & \text { Firas } & \text { DEF-grass }\end{array}$

Intended meaning: 'AT THE MOMENT, Firas is watering the grass (I am upset he is doing so).'

d. *J-ESQI zad Pelhi:n Pelhi:n qaSid Firas Pez-zerৎ

3SG.M-water CT now Asp Firas DEF-grass

Intended meaning: 'It is WATERING THE GRASS that Firas is doing at the moment (I am upset that he is doing so).'

Deduced from the scenario in (12) and (13) is the fact that the items that move across to the left periphery, crossing

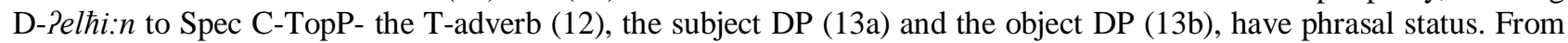
this it follows that those items with head status, the aspectual marker (13c) and the lexical verb (13d) cannot. This would follow from the fact that D-Pelhi:n is head, causing intervention effects to movement of the items of the same morphosyntactic status, i.e., inhibiting movement of head items.

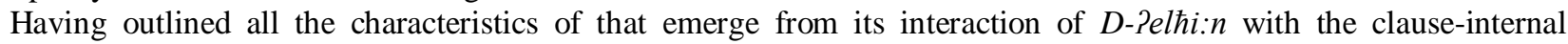
constituents in the clause, and having determined the categorial status of it, it is now relevant to launch the analysis task, adopting Rizzi’s (1997) split CP system.

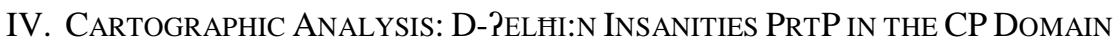

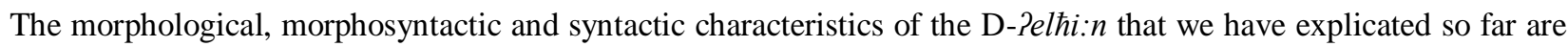
in line with a widespread assumption in the literature of grammaticalisation approach that items that develop functional properties are, hence, discourse particles, and turn syntactically into heads that instantiate discourse related projection and that the relevant grammaticalised item is the morphological realisation of the relevant discourse feature hosted by the discourse head. In the following subsection, the syntax of the D-Pelhi:n is examine, by adding more articulated material in the clause, attempting to detect the exact position the D-?elhi:n occupies that could eventually map the left periphery of HA with respect to D-?elhi: $n$.

\section{A. D-Pelhi:n First Merges in a CP-Layer}

\footnotetext{
${ }^{1}$ Merger of $z a d$ in (12) and its lack in (9e), while in both cases the dislocated AdvP $2 E H I: N$ is contrastively stressed, might be due to the assumption that in (9e) expresses Contrastive Focus rather than Contrastive Topic.

2 The contrastively stressed items are here argued to function as contrastive topic, which in syntax need to move to the left periphery, to the Spec position of C-TopP headed by the CT particle zad, following Alshamari and Holmberg (2019a, b).
} 
Following Munaro and Poletto (2003, 2005), who propose that the grammaticalised discourse particle po, discussed in sub-section 3.1, instantiates a particle phrase, which they notate as PrtP, with the head Prt (cf. Bayer \& Trotzke, 2015), represented in (14) below.

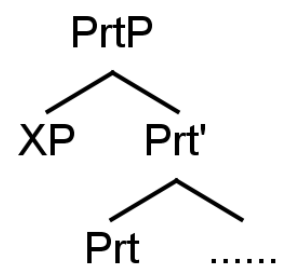

This state of affairs has been widely entertained. Following this generative cartographic enterprise, for instance, Paul (2009) assumes a CP-position for the grammaticalised discourse particle ou, encoding speaker/hearer's attitude 'warning a reminder'. Given this line of logic and the assumptions formulated above, it is now argued that the DPelћi: $n$ heads a discourse phrase, PrtP, taking semantically wide scope over the clause it is merged in. Consider (6a), repeated below in (15) but containing a wh-phrase leIf 'why' splitting off D-Pelhi:n from the propositional-TP.

(15) Pelhi:n leIf t'alab-t-uh xidmah ?ems

PRT why ask.PST-2SG.M-3SG.M help yesterday

w hu t'anif-uk qebul ?ems

while he ignore.PST.3SG.M-2SG.M before yesterday

'Why did you asked him for help yesterday while he ignored you the day before (I am upset you did so).'

It should be stressed here that D-Pelhi:n maintains a fixed relative order with respect to leIf; leIf cannot precede D-

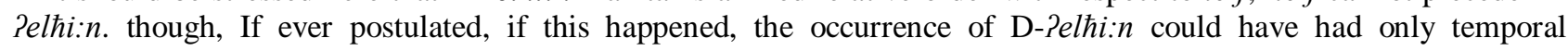

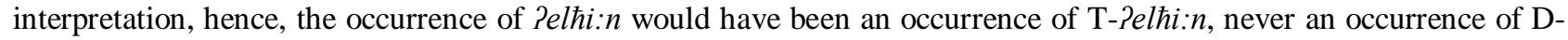

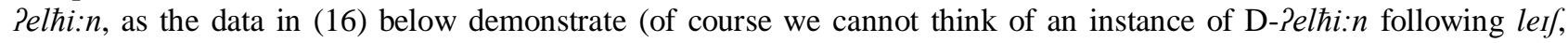

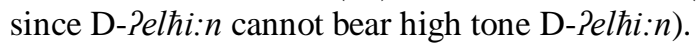

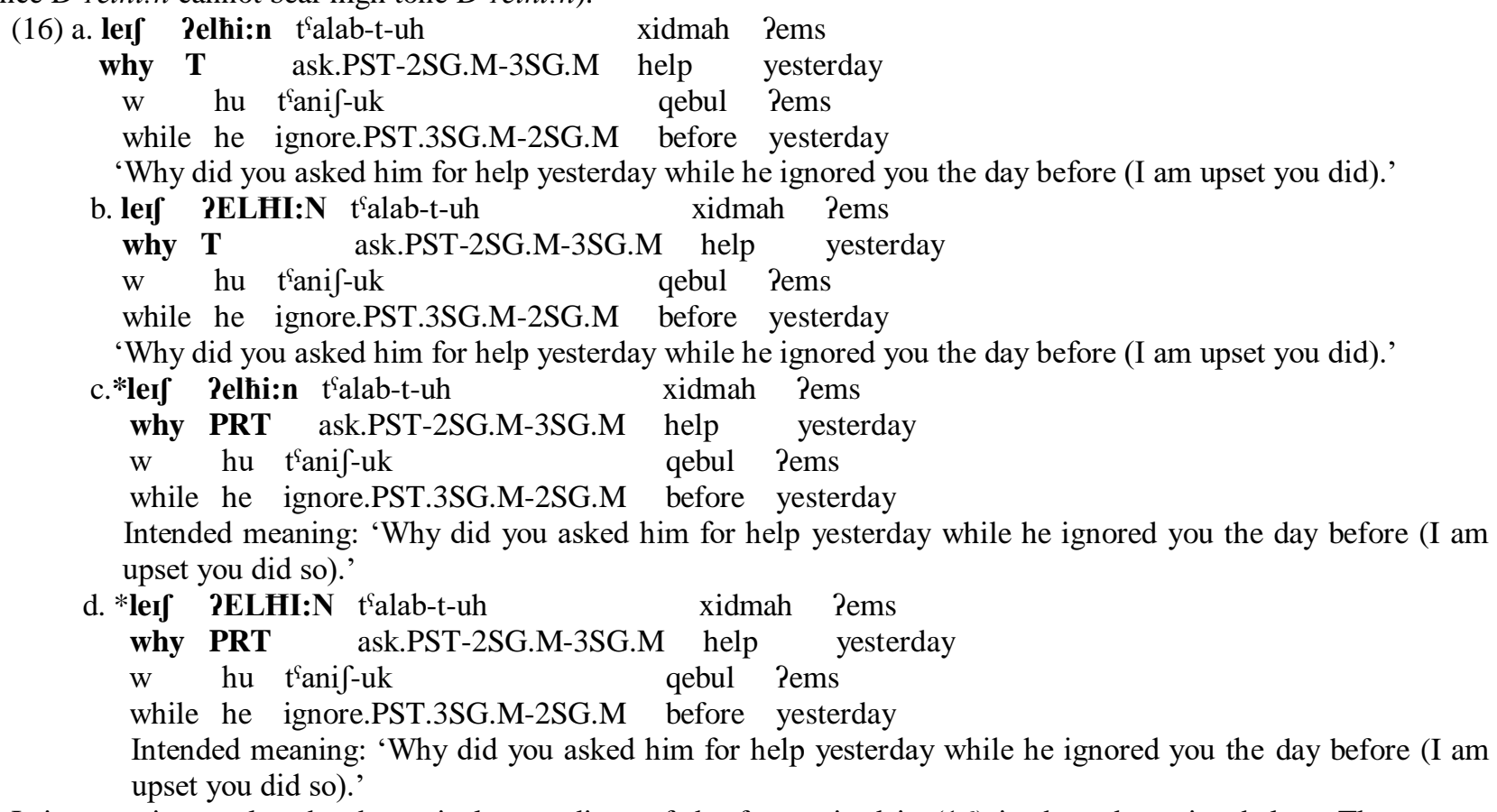

It is now time to lay the theoretical groundings of the facts raised in (16) in the sub-section below. Then, some implications and further consequences being imposed on the theory we follow here will be formulated.

\section{B. Cartographic View on D-Pelhi:n: Rizzi's (1997) Split CP}

Given that a wh-phrase is inherently focussed (Rizzi, 1997) and using leIf as a diagnostic in the spine of the structure

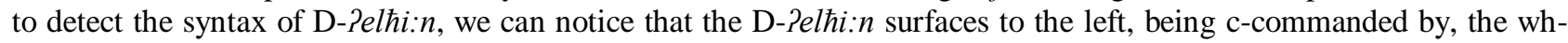
phrase leIf, which in Najdi Arabic moves to Spec FocP (Ouhalla, 1997; Alshamari, 2017a,b), an observation which

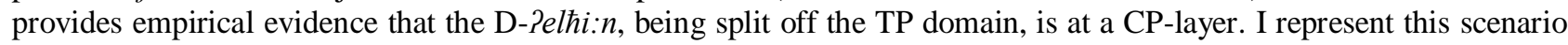
in (17) below. 


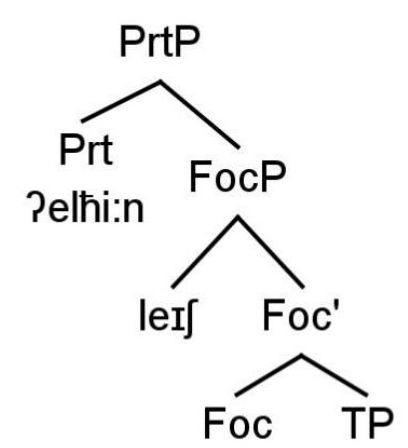

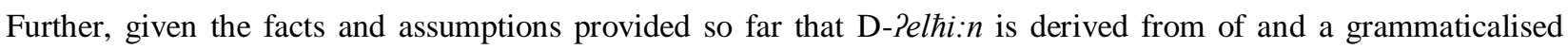

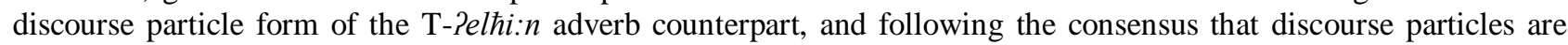
immobile in syntax (Struckmeier, 2014; Struckmeier, 2017; Alshamari, 2017a,b), I follow Hack's (2014) argument that

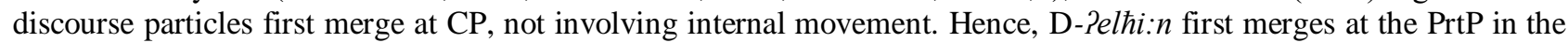
CP domain of HA syntax. Given this logic, (9) above, which witnesses an occurrence of D-?elhi:n c-commanding an occurrence of T-Pel $i: n$, is represented in (18) below.

(18)

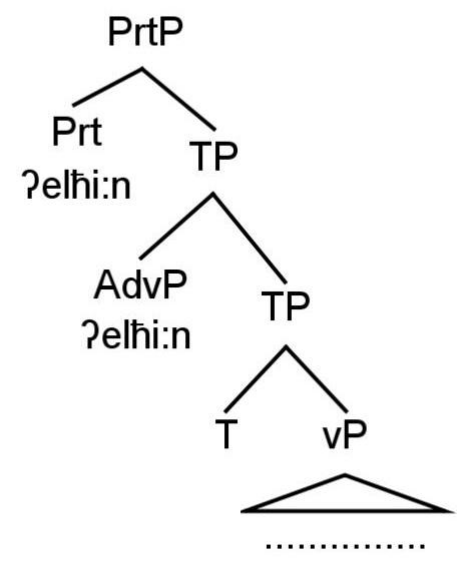

In par with this logic, the instances of the contrastively stressed constituents that precede D-?elhi: $n$ in (13), remerging at the Spec position of the C-TopP head, morphologically realised as the discourse particle zad which is endowed with the contrastive topic feature [C-Top], in a Spec head configuration Ouhalla (1997) following Chomsky (1995). I represent the case of the subject DP in (13a) in (19) below.

(19)

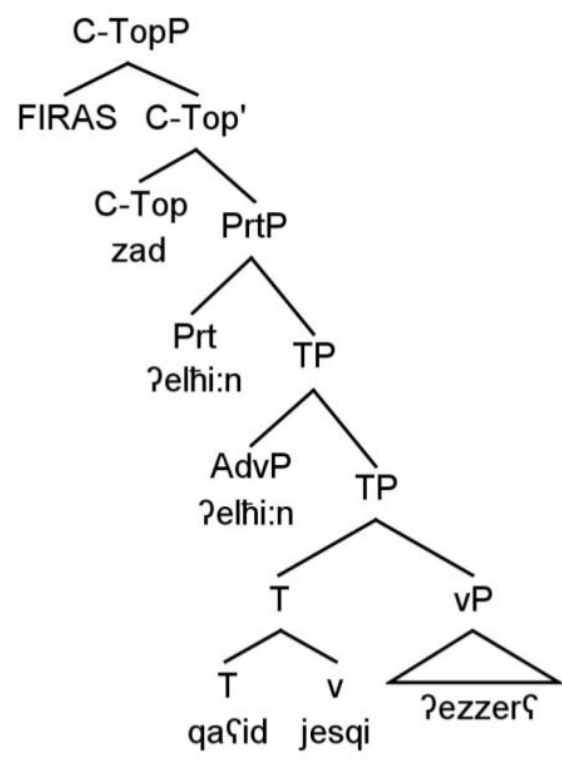


This means that D-Pelhi:n has its fixed position in syntax with respect to the other discourse items in the CP-layer, whence it semantically wide-scopes over the proposition expressed by the TP. TP-internal constituents that appear

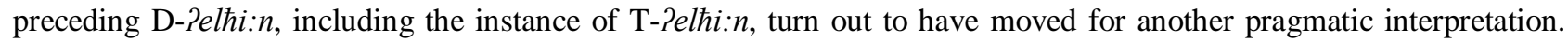
As the scenario in (19) shows, there is good evidence to believe that the other pragmatic interpretation the moving items receive is $\mathrm{C}$-topic, where evidence is provided by the fact that they bear contrastive stress and the fact that they seem to hold a spec head relation with the C-Topic particle zad (Alshamari \& Holmberg, 2019a,b). In all the cases we have scrutinized, this means that if a constituent moves out of the TP that happens to have been wide-scoped by D-?elhi:n,

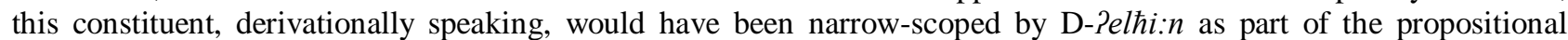
content expressed by the whole TP, before movement was initiated. Movement processes, intervention effects and

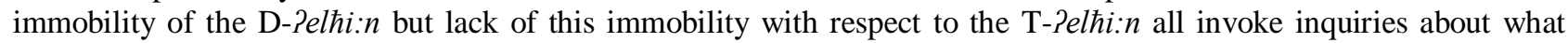
governs the rules in universal grammar across language, in terms of movement theory and discourse particles literature. This of course triggers further investigations on hopefully new set of data.

\section{CONCLUSION}

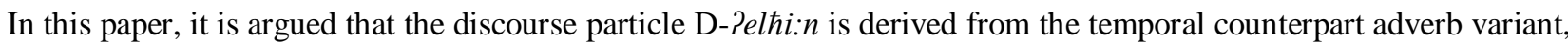
having undergone a grammaticalisation process, with the consequence that it has developed a discourse value, encoding a certain speaker attitude. Examining the left periphery of HA and scrutinizing more articulated discourse-related structure, it is shown that D-Pelћi:n merges clause-initially, has developed a head status, is not candidate for bearing high tone at the PF-interface, contra the characteristics of the its temporal adverb counterpart. Using the occurrence of a wh-phrase leIf 'why', which occupies Spec FocP in Rizzi's (1997) CP-system, it is shown that the D-?elhi:n first merges at a fixed CP-layer, heading a PrtP, and is immobile in its syntactic position, whence it semantically widescopes over the propositional-TP domain. From the syntactic behaviour of the TP-internal constituents that appear past

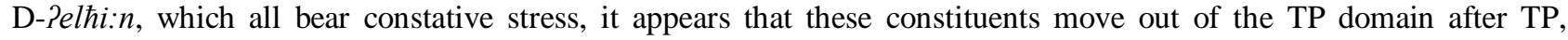

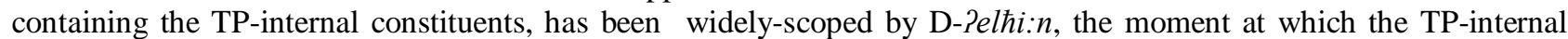
constituents move to get a contrastive topic interpretation, at the Spec of C-TopP headed by the C-Top marker zad.

\section{REFERENCES}

[1] Aijmer, K. (2002). English Discourse Particles: Evidence from a Corpus. Amsterdam. The Netherlands: John Benjamins.

[2] Alshamari, M. (2017a). Topic particles in the North Hail dialect of Najdi Arabic. Doctoral dissertation, Newcastle University.

[3] Alshamari, M. (2017b). A feature-based analysis of the syntax of the clause-initial particle вedı in North Hail Arabic. Poznan Studies in Contemporary Linguistics, 53(3), 305-344.

[4] Alshamari, M. \& Holmberg, A. (2019a). Topic particles, agreement and movement in an Arabic dialect. In 42nd GLOW (Generative Linguistics in the Old World) Conference. Newcastle University.

[5] Alshamari, M. \& Holmberg, A. (2019b). Topic particles, agreement and movement. In LAGB (Linguistics Association of Great Britina). Queen Mary University of London.

[6] Bayer, J. (2012). From Modal Particle to Interrogative Marker: a Study of German denn. Functional Heads. The Cartography of Syntactic Structures, eds. L. Bruge, A. Cardinaletti, G. Giusti, N. Munaro \& C. Poletto, 13-28. Oxford: Oxford University Press.

[7] Bayer, J. \& Trotzke, A. (2015). The derivation and interpretation of left peripheral discourse particles. In Josef. Bayer \& Roland. Hinterhölzl \& Andreas. Trotzke (eds). Discourse-oriented syntax. Amsterdam: John Benjamins Publishing Company. 226: $13-40$.

[8] Bayer, J \& Struckmeier, V (ed.). (2017). Discourse particles: Formal approaches to their syntax and semantics. Walter de Gruyter GmbH \& Co KG, 2016.

[9] Bertin, A. (2001). Maintenant:uncasdegrammaticalisation? Lang.française 130, 42--64.

[10] Biberauer, T. and Sheehan, M. (2011). 'Introduction: particles through a modern syntactic lens'. The Linguistic Review 28: $387-410$.

[11] Biberauer, T, Haegeman, L. \& Kemenade, A. (2014). Putting our heads together: towards a syntax of particles. Studia Linguistica 68: 1-15.

[12] Bolinger, D. (1989). Intonation and its uses. Melody in grammar and discourse. London: Edward Arnold.

[13] Büring, D \& Katharina, H. (2001). The syntax and semantics of focus-sensitive particles in German. Natural Language and Linguistic Theory 19: 229-281.

[14] Brinton, L. (1996). Pragmatic Markers in English. Grammaticalization and Discourse Functions. Berlin: Mouton de Gruyter.

[15] Cardinaletti, A. (2011). German and Italian modal particles and clause structure. The Linguistic Review (28/4): $493-531$.

[16] Chomsky, N. (1995). The minimalist program. Cambridge: MIT Press.

[17] Chomsky, N. (1999). Derivation by phase. MIT, Department of Linguistics. Vol. 18: 1-52

[18] Chomsky, N. (2000). 'Minimalist Inquiries: The Framework'. In H. Lasnik, R. Martin, D. Michaels and J. Uriagereka (eds) Step by step.' essays on minimalist syntax in honor of Howard Lasnik. Cambridge: MIT Press.

[19] Chomsky, N. (2001). 'Derivation by phase'. In M. Kenstowicz (ed) Ken Hale. A Life in Language. Cambridge: MIT Press. 152.

[20] Coniglio, M. (2008). Modal particles in Italian. Working Papers in Linguistics. 18: 91-129.

[21] Coniglio, M. \& Zegrean, Iulia. (2010). Splitting up Force, evidence from discourse particles. Linguistics 20: 7-34 
[22] Cuenca, M. J. (2013). The fuzzy boundaries between discourse marking and modal marking. Discourse markers and modal particles. Categorization and description, 66-2, 191-216.

[23] Frascarelli, M. and Hinterhölzl, R. (2007). Types of topics in German and Italian. In S. Winkler and K. Schwabe (eds.) On Information Structure, Meaning and Form. Amsterdam: John Benjamins. 87-116.

[24] Fraser, B. (1996). Pragmatic markers. Pragmatics (6), 167--190.

[25] Gonen, E., Livnat, Z., \& Amir, N. (2015). The discourse marker axshav ('now') in spontaneous spoken Hebrew: Discursive and prosodic features. Journal of Pragmatics, 89, 69-84.

[26] Hack, F. M. (2014). 'The Particle Po in the Varieties of Dolomitic Ladin-Grammaticalisation from a Temporal Adverb into an Interrogative Marker'. Studia Linguistica 68: 49-76.

[27] Haegeman, L. (1993). The interpretation of the particle da in West Flemish. Lingua (55) 90:111-128.

[28] Hirschberg, J. and D. Litmann. (1993). Empirical studies on disambiguation of cue phrases. Computational Linguistics 19: 501-30.

[29] Holmberg, A, Michelle, S \& Jenneke VDW. (2019). Movement from the double object construction is not fully symmetrical. Linguistic Inquiry 50(4). 677-722.

[30] Holmberg, A. (2020). On the bottleneck hypothesis of Verb Second in Swedish. In Rethinking Verb Second (pp. 40-60). Oxford University Press.

[31] Jarrah, M. (2017). Subject extraction in Jordanian Arabic (Doctoral dissertation, Newcastle University).

[32] Jarrah, M, Harb, M. (2021). Grammatical Encoding of Discourse Structure: A Case Study of Arabic Discourse Particle Tara. Transactions of the Philological Society, 119: 83-104.

[33] Jarrah, M \& Alshamari, M. (2017). The syntax of the evidential particle Jikil in Jordanian Arabic. Italian Journal of Linguistics, 29, 29-56.

[34] Jarrah, M. (2019). Record your Agree: A case study of the Arabic complementizer Pinn. Journal of Linguistics, 55(1), 83-122.

[35] Jarrah, M., \& Abusalim, N. (2021). In favour of the low IP area in the Arabic clause structure: Evidence from the VSO word order in Jordanian Arabic. Natural Language \& Linguistic Theory, 39(1).

[36] Munaro, N. \& Poletto, C. (2003). Sentential Particles and Clausal Typing in the Veneto Dialects. University of Venice Working Papers in Linguistics 13:127-154.

[37] Munaro, N. \& Poletto, C. (2005). On the diachronic origin of sentential particles in North-Eastern Italian dialects. Nordic Journal of Linguistics 28(2):247-267.

[38] Ouhalla, J. (1994). 'Verb movement and word order in Arabic', In D. Lightfoot and N. Hornstein (eds). Verb Movement. Cambridge: Cambridge University Press.

[39] Ouhalla, J. (1997). Remarks on focus in Standard Arabic. In M. Eid and R. R. Ratcliffe (eds). Perspectives on Arabic linguistics X: papers from the Tenth Annual Symposium on Arabic Linguistics. Amsterdam: John Benjamins. 9-45.

[40] Ouhalla, J. (2003). Functional categories and parametric variation. Routledge.

[41] Ouhalla, J. (2016). Root-extraction: Roots, verbs and nouns 'need'in Arabic. Brill's Journal of Afroasiatic Languages and Linguistics, 8(1), 200-222.

[42] Ouhalla, J., \& Shlonsky, U. (2002). Themes in Arabic and Hebrew syntax (Vol. 53). Springer Science \& Business Media.

[43] Paul, W. (2009). 'Consistent disharmony: sentence-final particles in Chinese'. Cambridge Occasional Papers in Linguistics 5: $1-24$

[44] Poletto, C. \& Zanuttini, R. (2003). Making Imperatives: evidence from Central Rhaeto-Romance. The Syntax of Italian Dialects, ed. C. Tortora, 175-206. Oxford: Oxford University Press.

[45] Rizzi, L. (1997). The fine structure of the left periphery. In L. Haegeman (ed). Elements of Grammar. Dordrecht: Kluwer Academic Publishers. 281-337.

[46] Rizzi, L. (2006). On the form of chains: Criterial positions and ECP effects. Current Studies in Linguistics Series, 42, 97-134.

[47] Roberts, I., \& Roussou, A. (1999). A formal approach to "grammaticalization". Journal of Linguistics, (55) 1: 871-905.

[48] Schiffrin, D. (1987). Discourse markers. Cambridge: Cambridge University Press.

[49] Shlonsky, U. (2000). 'Remarks on the Complementizer layer of Standard Arabic'. In J. Lecarme, J. Lowenstamm and U. Shlonsky (eds). Research in Afroasiatic Grammar: Papers from the Third conference on Afroasiatic Languages, Sophia Antipolis, France, 1996. Amsterdam/Philadelphia: John Benjamins Publishing.

[50] Stenström, A.-B. (1990). Lexical items peculiar to spoken discourse. In Svartvik (ed.). 137-175. The London-Lund Corpus of Spoken English: Description and Research. Lund." (1990).

[51] Struckmeier, V. (2014). Ja doch wohl C? Modal Particles in German as C-related elements'. Studia Linguistica 68: 16-48.

[52] Trotzke, A., \& Mayol, L. (2021). Catalan focus markers as discourse particles. Journal of Linguistics, (57) 4. 1-35.

[53] Traugott, E.C. (1995). The role of discourse markers in a theory of grammaticalization. Paper given at ICHL XII, Manchester.

[54] Van Baar, T. (1996). Particles. In Devriendt, B., Goossens, L. and J. van der Auwera (eds). Complex structures: A functionalist perspective. Berlin \& New York:Mouton de Gruyter. 259-301.

[55] Zimmermann, M. (2011). 'Discourse particles'. In C. Maienborn, K. von Heusinger and P. Portner (eds). Semantics: An international handbook of natural language meaning. Berlin: Mouton de Gruyter. 201Degand, Liesbeth and Simon Vandenbergen: 2012-2038.

Murdhy R. Alshamari is Assistant Professor of Theoretical Linguistics at the Department of English Language, The University of Ha'il, Ha'il, Saudi Arabia. He's obtained PhD in Theoretical Linguistics, Chomskyan theory of syntax from the University of Newcastle Upon Tyne, UK in 2017. Areas of interest subsume Minimalist practice of the generative framework of syntactic theory and Cartography approach to clause structure. Within strategies of these approaches, Murdhy's research contributions involve the syntax of discourse particles and Topics Typology, with respect to interface theory and agreement and movement as well as grammaticalisation as properties of natural language. Some of his contributions on the syntactic theory have been presented at world 
leading conferences, including (42nd GLOW, Generative Linguistics in the Old World 2019), LAGB Annual Meeting (QMU, 2019) and CamCoS 9 New (Cambridge Comparative Syntax in Newcastle, 2021).Contact: mr.alshamari@uoh.edu.sa 